\title{
Platelets as a Novel Source of Pro- Inflammatory Chemokine CXCL14
}

\author{
Alexander Witte Madhumita Chatterjee Florian Lang Meinrad Gawaz \\ Medizinische Klinik III, Kardiologie und Kreislauferkrankungen, Universitaet Tuebingen, Tuebingen, \\ Germany
}

\section{Key Words}

Platelets $•$ Chemokines $\bullet$ Chemotaxis $•$ Angiogenesis

\begin{abstract}
Objective: Platelets are a major source of chemokines. Here, we demonstrate for the first time that platelets express significant amounts of CXCL14 and disclose powerful effects of plateletderived CXCL14 on monocyte and endothelial migration. Methods: The expression of CXCL14 in platelets and in the supernatant of activated platelets was analysed by immunoblotting, ELISA, and flow cytometry. The effect of platelet-derived CXCL14 on monocyte migration was evaluated using a modified Boyden chamber. The effect of CXCL14 on monocyte phagocytosis was tested by using fluorochrome-labelled E.coli particles. The effect of platelet-derived CXCL14 on endothelial migration was explored by the use of an endothelial scratch assay. Results: Hitherto unrecognized expression of CXCL14 in human and murine platelets was uncovered by immunoblotting. Activation with platelet agonists such as adenosine-di-phosphate (ADP), collagen-related peptide (CRP), or thrombin-receptor activating peptide (TRAP), increased CXCL14 surface expression (flow cytometry) and release into the supernatant (immunoblotting, ELISA). Since CXCL14 is known to be chemotactic for CD14+ monocytes, we investigated the chemotactic potential of platelet-derived CXCL14 on human monocytes. Activated platelet supernatant induced monocyte migration, which was counteracted upon neutralization of platelet-derived CXCL14 as compared to IgG control. Blocking of the chemokine receptor CXCR4, but not CXCR7, reduced the number of migratory monocytes towards recombinant CXCL14, suggesting the involvement of CXCR4 in the CXCL14-directed monocyte chemotaxis. Recombinant CXCL14 enhanced the phagocytic uptake of E.coli particles by monocytes. In scratch assays with cultured endothelial cells (HUVECs), platelet-derived CXCL14 counteracted the pro-angiogenic effects of VEGF, supporting its previously recognized angiostatic potential. Conclusions: Platelets are a relevant source of CXCL14. Platelet-derived CXCL14 at the site of vascular lesions might play an important role in vascular repair/regeneration.
\end{abstract}

\section{Introduction}

Platelet-derived chemokines, which are released from activated platelets, play a regulatory role in thrombo-inflammation [1, 2]. Platelet-derived chemokines regulate 
migration and differentiation of monocytes into macrophages/foam cells [3, 4]. Furthermore, platelet-derived chemokines such as CXCL12 regulate migration and recruitment of circulating endothelial progenitor cells [5-8]. Thereby, platelet-derived chemokines maintain the balance between vascular inflammation as opposed to vascular repair [9]. Platelets also harbor several angiogenic and angiostatic factors, which are sorted into different subsets of $\alpha$-granules and preferentially released upon specific agonist-induced activation depending on physiological needs $[10,11]$.

CXCL14, also known as BRAK, BMAC or Mip-2 $\gamma$, is a relatively newly discovered chemokine. It is constitutively expressed in cutaneous cells, such as keratinocytes, dermal fibroblasts and dermal endothelial cells $[12,13]$. CXCL14 is further expressed in several immune cell types, such as immature dendritic cells (iDCs), monocyte-derived dendritic cells (DCs), activated B-cells and activated isolated human monocytes [14-16]. CXCL14 is known to act as a chemotactic agent for human B-cells, THP-1 cells, activated human natural killer cells (NKs), human and murine iDCs as well as human monocytes [12, 13, 16-19]. Cutaneous CXCL14 is involved in the recruitment of CD14 ${ }^{+}$DC precursors and in driving their differentiation into Langerhans cells [13]. CXCL14 thus plays a role in immune modulation. Beside its direct immune modulatory effects, CXCL14 inhibits the migration of endothelial cells, thus modulating angiogenic processes as an angiostatic chemokine [20]. CXCL14 mRNA levels are upregulated in the left anterior descending coronary artery (LAD) of obese pigs as a result of a high-fat diet [21]. This observation, combined with the chemotactic activities of CXCL14, its presence in different circulating blood cells and its contribution to angiogenesis suggest that CXCL14 could play a hitherto undiscovered but substantial role during the onset and progression of atherosclerosis or during vascular regeneration the site of vascular damage.

Platelets are active players in atheroprogression and decisive for thromboinflammation [1]. Upon activation platelets release macrophage-migration inhibition factor (MIF) or stromal cell-derived factor-1 (SDF-1/CXCL12) [5, 22], engage a wide range of chemokine receptors like CXCR2, CXCR4, CXCR7 to impose both autocrine and paracrine effects on interacting cells in the platelet micro-environment [23]. Platelet-derived CXCL12 is a chemokine, which acts as a regulator of monocyte adhesion, survival, and migration of monocytes through its receptors CXCR4 and CXCR7 [4]. CXCL12 and CXCL14 are similar in structure and considered primordial chemokines due to the sequence conservation among different species $[24,25]$.

The present study explored, whether platelets contain and are able to release CXCL14 in a similar manner like CXCL12. In this study, we show for the first time that human platelets indeed express CXCL14 and release it upon activation. Platelet-derived CXCL14 elicits a chemotactic response of human monocytes and inhibits endothelial proliferation, thus counteracting angiogenesis.

\section{Materials and Methods}

\section{Materials}

Recombinant human CXCL14/BRAK, recombinant human CXCL12/SDF-1, mouse anti-humanCXCL14/BRAK neutralizing mAb, mouse anti-human-CXCR4-mAb, mouse-anti-human-CXCR7-mAb, and mouse $\operatorname{IgG}_{2 \mathrm{~A}}$ isotype control mAb were purchased from R\&D (Minneapolis, MN, USA). Mouse control IgGs were from Santa Cruz Biotechnologies (Dallas, TX, USA). Rabbit anti-human-CXCL14/BRAK-pAb and rabbit anti-human-Actin-pAb were from Abcam (Cambridge, UK). FITC-labeled anti-human-CXCL14/ BRAK antibody was purchased from Biorbyt (Cambridge, UK) and FITC-labeled anti-human-CD62P from DAKO (Santa Clara, CA, USA). To measure platelet CXCL12 surface expression, mouse anti-human-CXCL12$\mathrm{mAb}$ (R\&D Systems) was used, following labeling with fluorescein isothiocyanate (FITC)], purchased from Sigma-Aldrich (St. Louis, MO, USA). RPMI-1640 medium and streptomycin/penicillin, were also purchased 


\section{Cellular Physiology Cell Physiol Biochem 2017;41:1684-1696

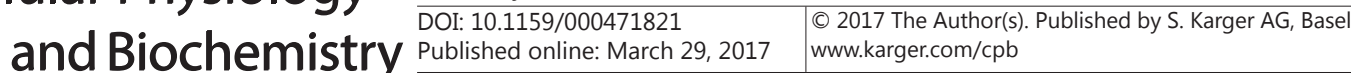

Witte et al.: Platelets as Source of CXCL14

from Sigma-Aldrich. Alexa Fluor ${ }^{\circledR} 488$ labeled E. coli (K-12 strain) BioParticles®, Ficoll-Paque and fetal calf serum (FCS) were purchased from Thermo Fisher (Waltham, MA, USA). VascuLife ${ }^{\circledR}$ VEGF Cell Culture Medium for HUVECs was purchased from Lifeline, (Carlsbad Ca, USA).

\section{Isolation of human platelets}

Washed human platelets were isolated as described previously [26]. In short, venous blood was drawn and collected in acid-citrate-dextrose (ACD)-buffer (1:4). After centrifugation at $209 \mathrm{x}$ g for 20 minutes platelet-rich plasma (PRP) was collected. The PRP thus obtained was added to Tyrodes-HEPES buffer ( $\mathrm{pH}$ 6.5) and centrifuged again at $836 \mathrm{x}$ g for 10 minutes. After removing the supernatant the resultant platelet pellet was resuspended in calcium containing PBS (pH 7.4, supplemented with $0.9 \mathrm{mM} \mathrm{CaCl}_{2}$ and $0.5 \mathrm{mM}$ $\mathrm{MgCl}_{2}$ ) and the platelet count was estimated by Sysmex. The platelet count was adjusted to $1 \times 10^{9}$ platelets per ml.

For generating resting platelet supernatant (RPS) or activated platelet supernatant, washed platelets were either kept under resting conditions by the use of apyrase $(0.2 \mathrm{U} / \mathrm{ml}$; Sigma-Aldrich) and Prostaglandin $\mathrm{I}_{2}(10 \mu \mathrm{M}$; Calbiochem $)$ or activated with CRP $(5 \mu \mathrm{g} / \mathrm{ml})$, both for 1 hour. Afterwards, platelets were centrifuged at $340 \mathrm{xg}$ for 5 minutes, the supernatant was kept at $-20^{\circ} \mathrm{C}$ and the pellet was lysed in RIPA lysis buffer [27].

\section{Isolation of murine platelets}

Platelets were obtained from 10- to 12-week-old C57Bl/6J mice as described previously [28]. In short, after anesthesia with isoflurane, blood was drawn from the retro-orbital plexus into tubes with ACD-buffer (1:4). Afterwards, PRP was washed with Tyrodes buffer ( $\mathrm{pH}$ 6.5) via centrifugation at $640 \mathrm{~g}$ for 5 minutes to pellet the platelets. Then platelets were lysed in RIPA lysis buffer for Western blot analysis. All animal experiments were conducted according to the animal protection law of Germany and were approved by local ethical authorities.

\section{Harvesting of murine organs}

10- to 12 -week-old C57Bl/6J mice were sacrificed in isoflurane, the thorax was opened, PBS was injected into the heart and organs were rinsed to remove remaining blood [29]. Liver, lung, kidney and heart were removed and tissue homogenates were treated with RIPA lysis buffer.

\section{Isolation of human monocytes}

Human monocytes were isolated as described [30]. In short peripheral blood monocytes were isolated through differential gradient centrifugation in Ficoll gradient ( $840 \mathrm{x} \mathrm{g}, 20 \mathrm{~min})$, followed by adhesion depletion on a plastic surface. Monocytes were cultured in RPMI-1640 supplemented with $10 \%$ fetal calf serum, $100 \mathrm{U} / \mathrm{ml}$ penicillin, $100 \mu \mathrm{g} / \mathrm{ml}$ streptomycin, and $2 \mathrm{mM} \mathrm{L-glutamine} \mathrm{at} 37^{\circ} \mathrm{C}$ and $5 \% \mathrm{CO}_{2}$ in a humidified atmosphere. Non-adherent cells were removed by gentle washing with PBS on the following day and the remaining adherent cells were harvested.

\section{Immunoblot analysis}

Cells or tissues were lysed with RIPA lysis buffer with added protease and phosphatase inhibitor (Roche). Afterwards, lysates were separated by SDS-PAGE under reducing conditions, transferred to a PVDF membrane and analyzed by immunoblotting. Primary antibodies used were rabbit anti-human-CXCL14$\mathrm{pAb}$ and rabbit anti-human-actin-pAb (Abcam). Equal loading was verified by actin immunostaining. To compare relative CXCL14 content in resting and activated platelets supernatants, same volumes of centrifuged activated/resting supernatant from platelets $\left(1 \times 10^{9} / \mathrm{ml}\right)$ were applied. Suitable secondary antibodies were from Li-Cor (Bad Homburg, Germany). The Li-COR Odyssey System was used for Western blot detection according to the manufacturer's instructions [31].

ELISA

Human CXCL14 ELISA (R\&D Systems) was carried out according to the manufacturer's protocol. Platelet supernatant was obtained by incubation of platelets $\left(1 \times 10^{9} / \mathrm{ml}\right)$ on $1 \%$ BSA (as control) or on a $0.1 \%$ collagen coated well plate for 1 hour. After centrifugation at $340 \mathrm{x} \mathrm{g}$ for 5 minutes, the supernatant was collected. Collagen coating led to the generation of activated platelet supernatant in comparison with BSA-coated wells where the supernatant served as resting control. 


\section{Cellular Physiology Cell Physiol Biochem 2017;41:1684-1696 \begin{tabular}{ll|l} 
DOI: 10.1159/000471821 & C 2017 The Author(s). Published by S. Karger AG, Basel \\
www.karger.com/cpb
\end{tabular} Witte et al.: Platelets as Source of CXCL14}

Surface-associated CXCL14 by flow cytometry analysis

Flow cytometry experiments were performed as described before [26]. In brief, $5 \mu$ l of PRP, adjusted to a count of $0.1 \times 10^{9} / \mathrm{ml}$, were diluted with $35 \mu \mathrm{l}$ of PBS with $0.9 \mathrm{mM} \mathrm{CaCl}_{2}$ and $0.5 \mathrm{mM} \mathrm{MgCl}_{2} .5 \mu \mathrm{l}$ of platelet agonist were added with the relevant fluorophore-labeled antibodies for an incubation time of $30 \mathrm{~min}$ in the dark at room temperature. For activation of platelets thrombin receptor activating peptide (TRAP; Sigma-Aldrich), collagen-related peptide (CRP; provided by Richard Farndale, University of Cambridge, United Kingdom) or adenosine-di-phosphate (ADP; Probe\&Go, Osburg, Germany) was used at the indicated concentrations and time points. After staining, the cells were fixed with $0.5 \%$ paraformaldehyde and analyzed on a FACS-Calibur Flow Cytometer (Becton-Dickinson, Heidelberg, Germany). Mean fluorescence intensity (MFI) was acquired as expression of a specific antibody binding and was used as a quantitative measurement of platelet proteins' surface expression [32].

\section{Chemotaxis Assay}

Migration of monocytes toward platelet-derived CXCL14, recombinant CXCL14 and CXCL12 was analyzed in a modified Boyden chamber (Neuro Probe Inc., Gaithersburg, MD, USA) with a 5- $\mu$ m pore polycarbonate membrane separating the upper from the lower compartment. Monocytes $\left(2 \times 10^{4}\right.$ cells/ well in RPMI-1640 medium; 1\% FCS, $100 \mathrm{U} / \mathrm{ml}$ penicillin, $100 \mu \mathrm{g} / \mathrm{ml}$ streptomycin) were loaded onto the upper chamber, and resting (RPS) or activated (APS) platelet supernatant or the mentioned recombinant proteins served as chemoattractants in the lower chamber. Neutralizing antibody against platelet-derived CXCL14 or respective isotype control $(10 \mu \mathrm{g} / \mathrm{ml})$ were also added along with APS as indicated for 30 minutes at RT, before loading. Chemokine receptors CXCR7 and CXCR4 were blocked on monocytes for 30 minutes at RT with mouse anti-human-CXCR4-mAb $(10 \mu \mathrm{g} / \mathrm{ml})$ or mouse anti-human-CXCR7-mAb (10 $\mu \mathrm{g} /$ $\mathrm{ml}$ ) and respective IgG controls before chemotaxis. After incubation for 4 hours at $37^{\circ} \mathrm{C}$ and $5 \% \mathrm{CO}_{2}$, in a humidified atmosphere, the membrane was fixed with $100 \%$ ethanol and stained with May-Grünwald/ Giemsa. The membrane was mounted on glass slides; the number of migrated cells was counted for each well in randomly selected microscopic fields at $\times 20$ magnification. Additionally, the number of migrated monocytes in the lower chamber was ascertained by running each sample for 2 minutes on a flow cytometer [4] at same flow rate (low).

\section{Phagocytosis Assay}

Human monocytes were pretreated with recombinant CXCL14 for 2 hours in RPMI-1640/FCS 1\%. Then Alexa Fluor ${ }^{\circledR} 488$ labeled E. coli (K-12 strain) BioParticles ${ }^{\circledR}$ were added to monocytes at a ratio of 10:1 in RPMI-1640/FCS $1 \%$ and incubated for 4 hours at $37^{\circ} \mathrm{C}$ and $5 \% \mathrm{CO}_{2}$ in a humidified atmosphere. Samples were fixed in 1\% paraformaldehyde and analyzed by flow cytometry. Trypan blue (10\%) (SigmaAldrich) was used to quench for surface fluorescence coming from adherent but not phagocytized E. coli BioParticles. The intracellular fluorescence signal was analyzed by flow cytometry.

\section{Endothelial monolayer scratch assay}

Human umbilical vein endothelial cells (HUVEC) were purchased from ATCC and cultivated in VascuLife $®$ VEGF Cell Culture Medium) at $37^{\circ} \mathrm{C}$ and $5 \% \mathrm{CO}_{2}$ in a humidified atmosphere. A scratch wound was applied on the confluent HUVEC monolayer in a 12-well-plate using a $200 \mu$ lip [6]. After the scratch, cells were washed gently with PBS to remove non-adhering cells. Cells were further incubated in the presence of complete medium and VEGF $(10 \mathrm{ng} / \mathrm{ml})$ alone, or along with recombinant CXCL14 (50 ng/ml), recombinant CXCL12 $(50 \mathrm{ng} / \mathrm{ml})$ or in combination with RPS/APS diluted in complete medium at a 1:2 ratio. Images of 3 identical fields per sample were captured at the indicated time points with a Zeiss Axiovert 200 microscope and the area of the gap was measured with AxioVision software by measuring the cell-free area of $1000 \mu \mathrm{m}$ of the gap. Measured areas were put in relation to their corresponding areas at the time point $\mathrm{T}_{0}$.

\section{Statistical analysis}

Data are presented as mean \pm S.E.M. All data were tested for significance using GraphPad Prism software (GraphPad Software, Inc., La Jolla, CA, USA) setting statistical significance at $\mathrm{P}<0.05$ for an unpaired t-test to compare two sets of data or for a one-way ANOVA using Dunnett post hoc test to compare multiple data sets. 


\section{Results}

The chemokine CXCL14 is expressed in platelets and secreted upon activation

Platelets store and release a variety of CXCL chemokines including CXCL12 and CXCL16 $[5,33]$. The release of platelet-derived chemokines results in modulation of platelet function (autocrine loop) and regulation of inflammation in the microenvironment of platelet accumulation (paracrine loop) [1]. Recently, another chemokine BRAK/CXCL14 has

Fig. 1. CXCL14 is present in human and murine platelets and is released upon activation. (A) Immunoblot analysis was performed with human and murine platelets and human monocyte lysates. CXCL14 (13kDa) was detected in platelet samples derived from humans and mice as well as in monocytes. $\beta$-actin ( $42 \mathrm{kDa}$ ) served as loading control. Data are representative of 3 immunoblot analyses. (B) As a control, CXCL14 expression in murine kidney, lung, liver and heart tissue is shown. Here, CXCL14 was detected as a $18 \mathrm{kDa}$ band. Data are representative of 3 independent analyses. (C) Flow cytometry experiments revealed that incubation of platelets with CRP $(5 \mu \mathrm{g} / \mathrm{ml})$ or TRAP $(25 \mu \mathrm{M})$ for 30 minutes significantly increased the surface expression of CXCL14 on platelets as compared to resting. CD62P surface expression served as a control for platelet degranulation. Data are Mean \pm SEM of 5 independent experiments. (D) CXCL14 is detectable in the supernatant of platelets. Supernatants were collected from platelets activated with CRP $(5 \mu \mathrm{g} / \mathrm{ml})$ for 60 minutes or from PBS-suspended platelets, which served as a control. Data are representative of 3 independent analyses. The release of CXCL14 was analyzed by ELISA in supernatants of platelets adhering to immobilized collagen or BSA. Data are Mean \pm SEM of 3 independent experiments. (E) Surface expression of CXCL14 on platelets follows a concentration-dependent response when CRP is used as an agonist. Substantially lower concentrations of CRP were required for surface expression of CXCL12 on activated platelets. Data are Mean \pm SEM of 4 independent experiments.

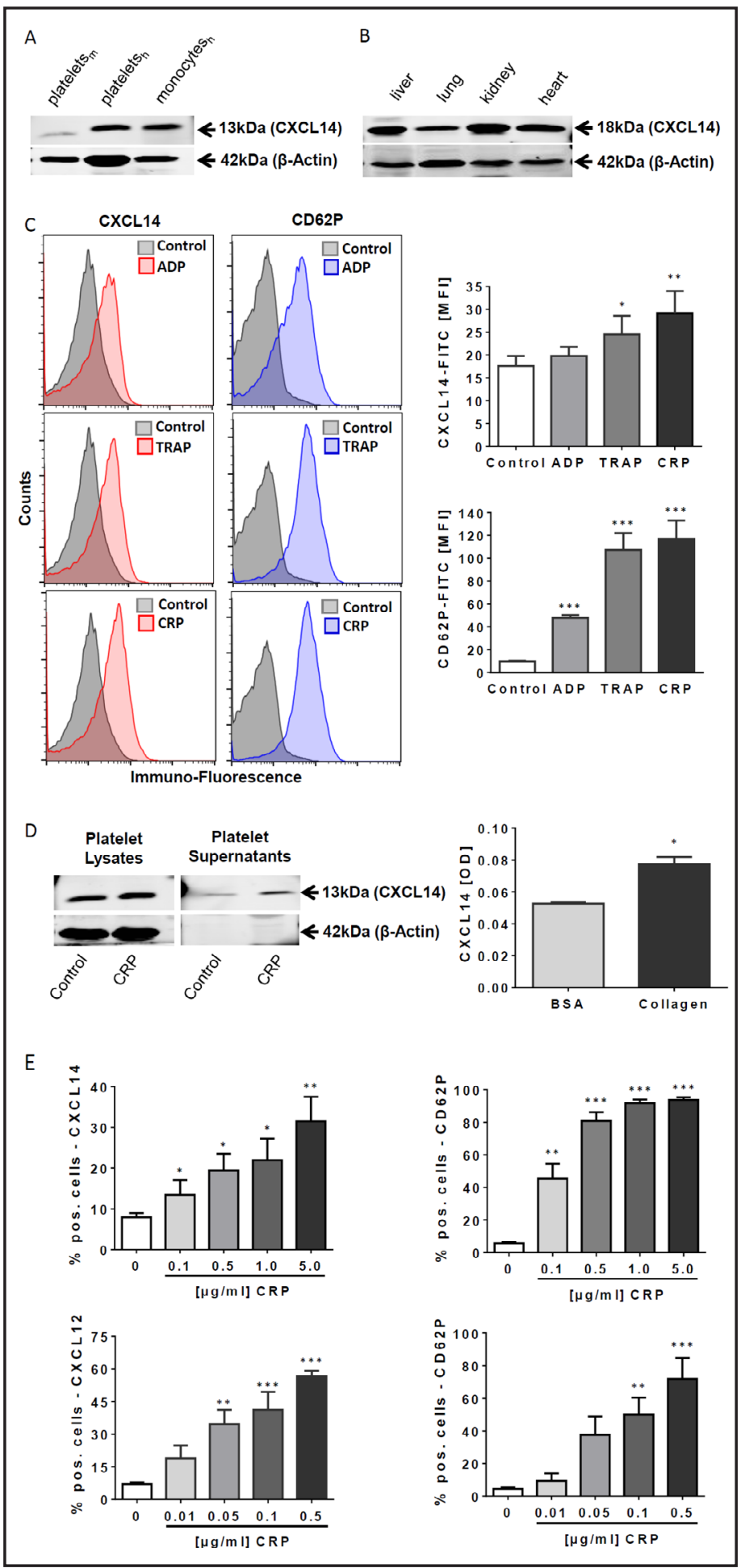


been identified as a potent chemotactic and angiostatic mediator [25]. The expression of CXCL14 in platelets is not known. Thus we explored, whether platelets express CXCL14 and validated its functional relevance in terms of platelet-associated inflammatory response. Thus, we evaluated isolated platelets from humans and mice using a specific anti-CXCL14$\mathrm{pAb}$ for immunoblotting. We found that platelets contain CXCL14 as indicated by the positive immunoreactive band (Fig. 1A). As positive control, lysates of human monocytes were used. Further, as described previously, CXCL14 was found in substantial amounts in mouse tissues from kidney, lung, liver, and heart (Fig. 1B). Next we asked whether CXCL14 is secreted upon platelet activation. Platelets were isolated and stimulated with agonists like ADP, CRP, and TRAP. We found that surface expression of CXCL14 was significantly enhanced upon activation, which was paralleled by the release of the activation marker CD62P (Fig. $1 \mathrm{C})$, denoting degranulation of $\alpha$-granule contents. Further, CXCL14 was released into the supernatant derived from activated platelets, as verified by immunoblotting and ELISA (Fig. 1D). To characterize the relative release of CXCL14 from platelets as compared to reported release of another chemokine CXCL12, we analyzed the number of CXCL14 ${ }^{+}$platelets to that of CXCL12 ${ }^{+}$platelets for different concentrations of CRP. CD62P was used as a control for platelet activation. In comparing the release of CXCL14 as compared to CXCL12 upon platelet stimulation, we observed that activation-triggered release kinetics of CXCL14 was comparable to the release kinetics of CXCL12. However, higher concentrations of the agonist $(1 \mu \mathrm{g} / \mathrm{ml}$ for CXCL12 as compared to $5 \mu \mathrm{g} / \mathrm{ml}$ for CXCL14) were required to drive CXCL14 release as compared to CXCL12 (Fig. 1E).

Platelet-derived CXCL14 stimulates migration of monocytes

CXCL14 has been described as a chemotactic factor for a variety of cells including dendritic cells, natural killer cells, and $\mathrm{CD} 14^{+}$monocytes [25]. Thus we asked, whether CXCL14 derived from platelets stimulates chemotaxis of monocytes as previously reported for CXCL12 [4]. In a modified Boyden chamber, supernatant derived from CRP-activated platelets was found to be chemotactic for human monocytes compared to supernatant from resting platelets. In the presence of neutralizing anti-CXCL14-mAb migration of monocytes was significantly reduced compared to IgG control (Fig. 2A). When recombinant CXCL14 was used, migration of monocytes was similar in extent as compared to recombinant CXCL12 (Fig. 2B). Compared to $1 \mu \mathrm{g} / \mathrm{ml}$ of CXCL12, CXCL14 showed a similar migratory effect on human monocytes at a concentration of $5 \mu \mathrm{g} / \mathrm{ml}$.

To further define the respective chemotactic receptor on monocytes responsible for driving CXCL14-initiated chemotactic response, CXCL14-dependent migration was analyzed in the presence of blocking anti-CXCR4 or anti-CXCR7-mAb. When compared to control IgG or anti-CXCR7-mAB, CXCL14-dependent migration of monocytes was significantly reduced in the presence of anti-CXCR4-mAb (Fig. 2C). This indicates that CXCR4 but not CXCR7 is the primary receptor for CXCL14 on monocytes to trigger a chemotactic response as previously reported for CXCL12 [4].

CXCL14 enhances phagocytic activity of monocytes

Chemokines such as CXCL12 have been reported to exert phagocytic activity of monocyte/macrophages [4]. Whether CXCL14 modulates monocyte phagocytosis is unknown. Monocytes were pre-treated with CXCL14 or diluent and phagocytosis of fluorochrome-labeled E.coli particles was analyzed as described [34]. We found that CXCL14 stimulated phagocytic uptake of E.coli particles by monocytes (Fig. 3), indicating a role of CXCL14 in innate immune response.

\section{Platelet-derived CXCL14 attenuates endothelial migration}

Platelet-derived chemokines (CXCL4, CXCL12) and growth factors (e.g. VEGF) are critical regulators of angiogenesis prompting both angiogenic and angiostatic responses under diverse pathophysiological circumstances [11]. CXCL14 has been previously described to exert angiostatic properties [20]. To further analyse the biological effect of platelet-derived 
Fig. 2. Platelet-derived CXCL14 induces monocyte migration mediated through the chemokine receptor CXCR4. (A) The effect of supernatant derived from activated platelets on monocytes was analyzed in a modified Boyden chamber in the presence of neutralizing anti-CXCL14-mAb or IgG control. Here the membrane was stained and the number of migrated monocytes was counted. Data are Mean \pm SEM of 5 independent experiments. (B) A dose dependent chemotactic effect of CXCL14 on human monocytes was observed; CXCL12 served as a positive control. The number of cells migrated into the lower well was deciphered via flow cytometry. Data are Mean \pm SEM of 5 independent experiments. (C) Pre-treatment of monocytes with blocking antibodies against the chemokine receptors CXCR4 and CXCR7 for 30 minutes showed a decreased number of migrating monocytes for anti-CXCR4-mAb treated monocytes in contrast to anti-CXCR7-mAb or IgG-treated cells. The number of cells migrated into the lower well was deciphered via flow cytometry. Data are Mean \pm SEM of 3 independent experiments.

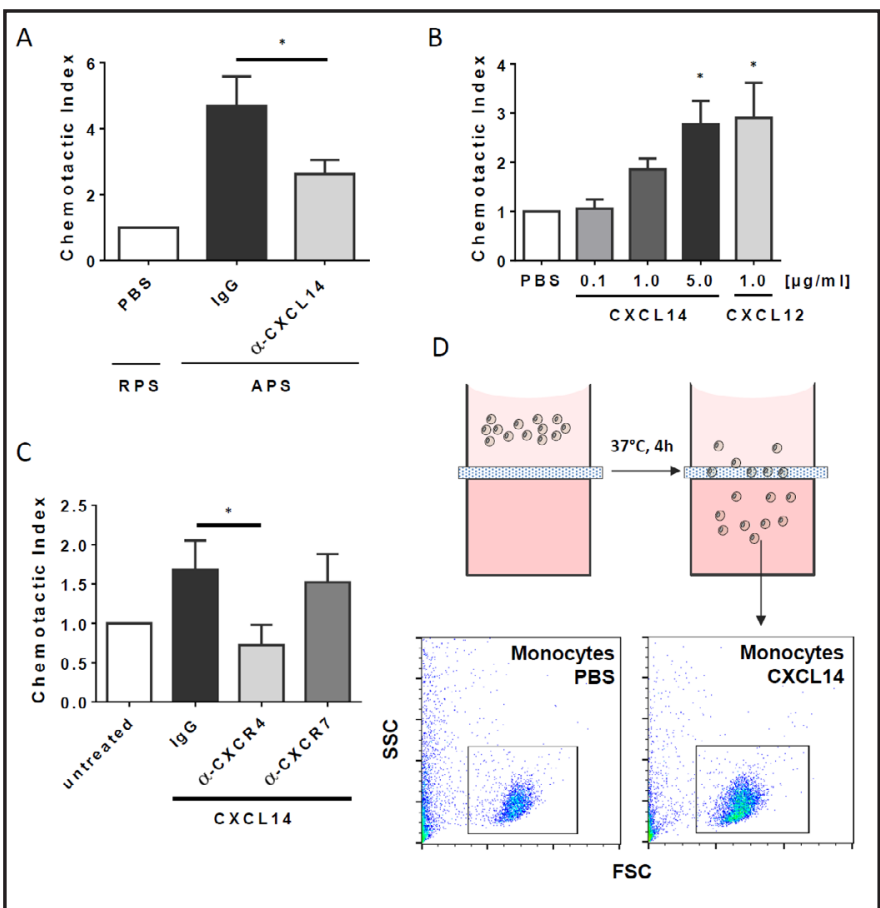

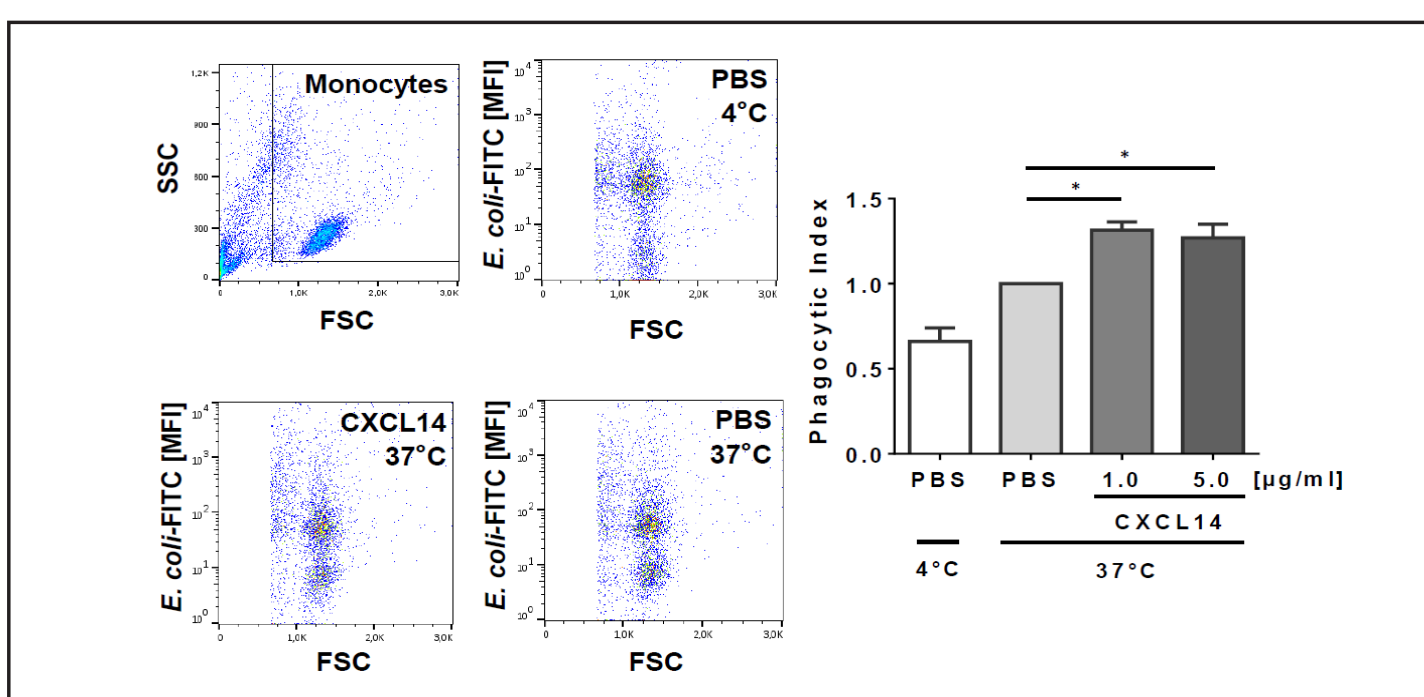

Fig. 3. CXCL14 increases the phagocytic activity of human monocytes. CXCL14 (1 $\mu \mathrm{g} / \mathrm{ml} ; 5 \mu \mathrm{g} / \mathrm{ml})$ increased the mean fluorescence intensity of isolated human monocytes, which phagocytized Alexa Flour@ 488 E. coli BioParticles $®$, to a significant extent as compared to control. Fluorescence was measured after quenching for surface-bound fluorescence signal with trypan blue using flow cytometry. Incubation at $4^{\circ} \mathrm{C}$ served as negative control for the phagocytosis assay. Data are Mean \pm SEM of 4 independent experiments.

CXCL14, we evaluated the impact of supernatants from CRP $(5 \mu \mathrm{g} / \mathrm{ml})$ activated platelets in an endothelial wound scratch assay. As shown previously, platelet-derived factors overall favour endothelial cell migration in this scratch assay [10]. When a neutralizing antiCXCL14-mAb was added to the culture medium, platelet-dependent endothelial migration was significantly enhanced as compared to IgG control (Fig. 4A). This indicates that platelet-derived CXCL14 inhibits re-endothelialization and migration of endothelial cells. 


\section{Cellular Physiology Cell Physiol Biochem 2017;41:1684-1696 \begin{tabular}{l|l|l} 
DOI: 10.1159/000471821 & a 2017 The Author(s). Published by S. Karger AG, Basel \\
www.karger.com/cpb
\end{tabular}

Fig. 4. Platelet-derived CXCL14 attenuates migration of human umbilical vein endothelial cells (HUVEC). (A) When incubated with neutralizing anti-CXCL14 antibody, treatment of HUVECs with activated platelet supernatant in a wound healing assay, showed a significantly accelerated closure of the scratched area as compared to IgG control. Cell images at 0 and 10 hours are shown. Data are Mean \pm SEM of 3 independent experiments. (B) Recombinant CXCL14 (50ng/ $\mathrm{ml}$ ) showed a delayed closure of the scratch area as compared to incubation with only VEGF $(10 \mathrm{ng} / \mathrm{ml})$ or VEGF and CXCL12 $(50 \mathrm{ng} / \mathrm{ml})$. Cell images at 0 and 10 hours are shown. Data are Mean \pm SEM of 3 independent experiments.

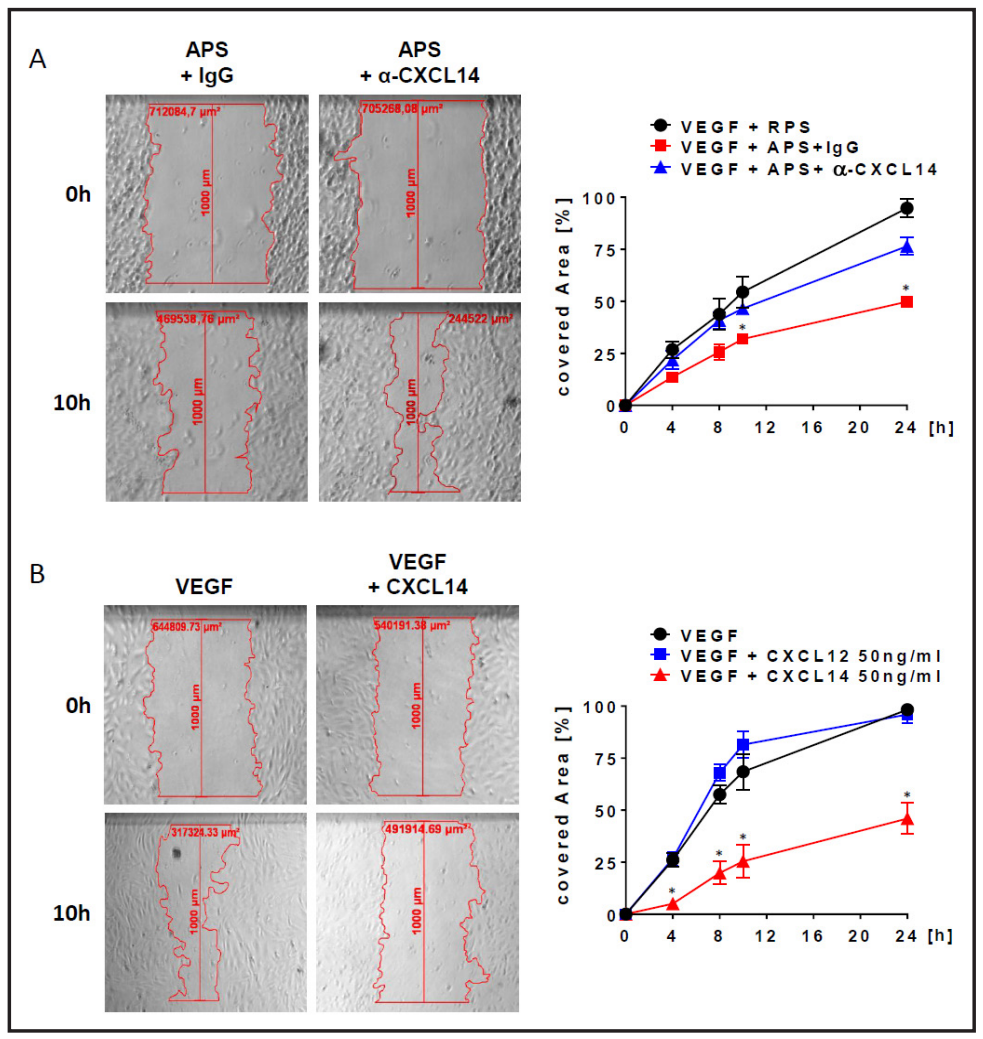

Fig. 5. Hypothetical role of platelet-derived CXCL14 at site of vascular injury. Platelets express and release CXCL14 upon activation. Platelets adhering to injured or inflamed endothelium or exposed to subendothelial matrix components (e.g. collagen) are activated and release several factors. Activated platelet-derived CXCL14 attracts monocytes at the site of platelet activation. Platelet-derived CXCL14 inhibits migration of endothelial cells and therefore modulates angiogenesis as an angiostatic chemokine. Therefore, at the site of vascular damage, activated platelet-derived CXCL14 might foster vascular inflammation

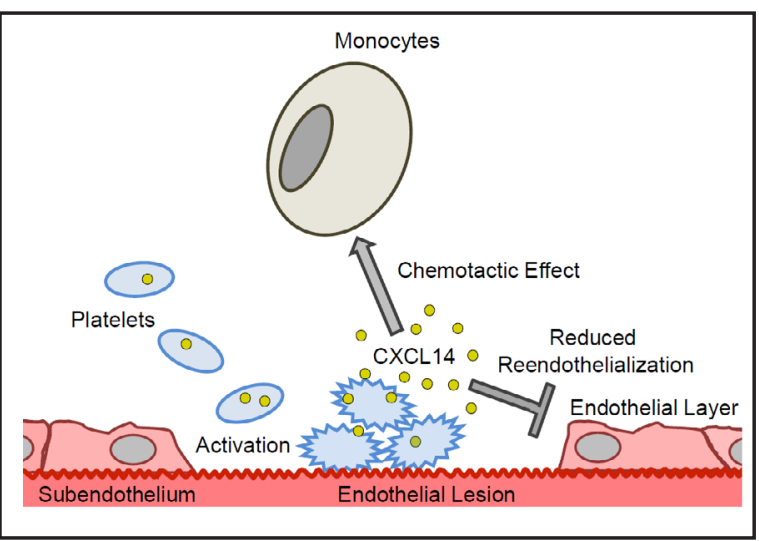
and prevent endothelial regeneration.

This conclusion is further supported by the experiment where the angiostatic response of recombinant CXCL14 was validated in this assay. In the presence of recombinant CXCL14 but not CXCL12, re-endothelialization was attenuated (Fig. 4B). This implies that plateletderived CXCL14 might exert a negative impact during endothelial repair and regeneration as opposed to CXCL12, and taken together with its chemotactic potential, might foster vascular inflammation by instigating monocyte migration to the site of endothelial damage where activated platelets adhere (Fig. 5).

\section{Discussion}

The major findings of the study are: i) platelets are a novel source of the chemokine CXCL14 and release CXCL14 upon activation. ii) CXCL14 derived from activated platelets 
stimulates migration of monocytes and iii) enhances the phagocytic uptake of E.coli particles by human monocytes. iv) Platelet-derived CXCL14 inhibits the migration of human umbilical vein endothelial cells (HUVECs). These findings imply that this hitherto unknown expression and release of CXCL14 from platelets lead to pro-inflammatory activity and regulate monocyte migration and phagocytosis, both critical mechanisms for immune-defense. Beyond its role in thrombo-inflammation, platelet-derived CXCL14 inhibits endothelial migration indicating angiostatic activity. Thus, platelet-derived CXCL14 modulates inflammation and angiogenic mechanisms, important aspects of immune defense and vascular/tissue repair.

Beyond thrombosis and haemostasis, platelets are important regulators in thromboinflammation and vascular/tissue repair after organ damage [35]. Platelets are a major source of CXC-chemokines including CXCL4 (PF4), CXCL11 [36], CXCL12 (SDF-1), CXCL16 [33] and CCL-chemokines, such as CCL5/RANTES [37], cytokines like IL1 [38-40] or chemokinelike cytokines such as MIF [41]. Chemokines like CXCL12 or CXCL4 recruit inflammatory and regenerative endothelial cells, modulate a pro- and anti-angiogenic response, and exert antimicrobial activities [4, 42, 43]. Platelets are a major source of chemokines and are able to release substantial amounts of chemokines rapidly within minutes into the microenvironment at the site of platelet accumulation. Thus, platelet-derived chemokines are powerful mediators of inflammation, immune defense, and repair mechanisms following vascular or tissue damage [11].

Previously, we identified CXCL12 to be present in platelets [5]. Platelet-derived CXCL12 has important aspects for vascular and tissue repair mechanisms by governing recruitment of monocytes and endothelial progenitor cells [35]. CXCL12 is expressed on the platelet surface and is released into the supernatant upon stimulation with agonists such as collagen or thrombin [5]. Platelet-derived CXCL12 on the one hand promotes pro-inflammatory monocyte migration and differentiation into macrophages/foam cells [4], while on the other hand substantiates the migration of progenitor cells and their subsequent differentiation into endothelial progenitor cells and augment neo-endothelialization or vascular regeneration as opposed to vascular inflammation both in vitro and in vivo [8].

CXCL14, also known as BRAK, is a chemokine of the CXC-chemokine family and is found in barrier tissue cells like keratinocytes, dermal endothelial cells, but also in several other blood-borne immune cell types like immature dendritic cells (iDCs), monocyte-derived dendritic cells (DCs) and upon activation also in B-cells and isolated human monocytes [25]. The expression of CXCL14 in platelets has not been reported yet, even in large proteomic studies [44]. We found that CXCL14 is present in substantial quantities in platelets, is exposed at the platelet surface and is released in a soluble form upon activation. Since plateletinflammatory or platelet-endothelial interactions play a decisive role in setting the course of vascular inflammation and regeneration, the discovery of platelet-derived CXCL14 adds a new dimension to the mechanistic regulation of vascular pathophysiology. Platelets being forerunners to the site of vascular injury, the pathophysiological significance of platelet-derived CXCL14 in initiating an inflammatory response by triggering inflammatory cell migration, or exert an angiostatic response or potential anti-microbial response against pathogenic intrusion as previously reported for recombinant CXCL14 is noteworthy. This could bear prominent significance also at the site of wound repair in barrier tissues. Platelet-derived CXCL14 could add to the amount of CXCL14 contributed by endothelial cells or keratinocytes present at the site of dermal wounds, support immune defence from migratory immune cells, facilitate microbial clearance and subsequently determine the course of wound repair.

Platelets harbour several functionally opposing factors e.g. pro-inflammatory as opposed to anti-inflammatory, pro-angiogenic as compared to anti-angiogenic, in their granular repertoire. Previously a spatial segregation of these factors has been shown in different subsets of $\alpha$-granules, also a preferential release mechanism was demonstrated following diverse agonists stimuli e.g. PAR1 mediated as opposed to PAR4 mediated [10]. Another effector mechanism by which platelets might govern the balance between functionally opposing responses is through difference in release kinetics or extent of these factors. The release kinetics of CXCL14 from platelets was similar as compared to CXCL12, 
since CXCL14 release could be detected within 30 minutes of stimulation. This is in contrast to MIF; another platelet derived pro-inflammatory mediator the release kinetics of which is considerably slower [41]. However, the release of CXCL14 from platelets required higher concentrations of agonists such as CRP as compared to CXCL12. This indicates that the release of both CXC-chemokines is regulated differentially and dependent on the strength of the stimulus. This might have important (patho)physiological consequences for paracrine inflammatory responses and endothelial function in the surrounding of activated platelets. Both CXCL14 and CXCL12 stimulate monocyte migration via the chemokine receptor CXCR4, indicating that both chemokines are ligands for CXCR4. Whereas CXCR4 is a well-recognized receptor for CXCL12 [9] the receptor for CXCL14 is poorly defined. Although it is clear that CXCL14 acts as a chemotactic factor for a variety of immune cells like NK cells, iDCs, activated B-cells and monocytes [25], a convincing evidence of the responsive receptor is still missing. A recent study demonstrates that CXCL14 does not counteract CXCL12-CXCR4-mediated responses [45], indicating that CXCR4 might not be a primary receptor for CXCL14. In our study, we found that blocking CXCR4 on monocytes by anti-CXCR4-mAb attenuates CXCL14dependent monocyte migration, which implies a role for CXCR4 as a receptor for CXCL14. However, additional studies are required to further disclose the role of CXCR4 for CXCL14dependent cell migration.

Previously and in the current study, we show that platelet releasate substantially promotes monocyte migration via CXCR4. Platelets released chemotactic factors include CXCL12 and MIF, which are known ligands for CXCR4 to govern monocyte migration [4, 41]. The present study adds a novel, CXCR4-responsive chemokine CXCL14 to be involved in platelet-mediated cell migration. MAb-based inhibiting of CXCL14 reduced the migration response of supernatant derived from activated platelets indicating that platelet-derived CXCL14 is a major monocyte attractant despite CXCL12 and MIF. Although we presently did not address the differential regulation of monocyte migration and the relative potential of CXCR4-responsive (CXCL12, CXCL14, MIF) towards platelet chemokines, it is tempting to speculate that these chemoattractants are involved dynamically during the migration response. Both CXCL12 and CXCL14 are rapidly released from activated platelets, however, the release of CXCL14 requires a much higher agonist concentration as CXCL12. Further, MIF follows much slower release kinetics as compared to CXCL12 [41]. Thus, the importance of CXCR4-responsive platelet chemokines may depend on strength and time of platelet activation which may have an impact in a variety of (patho)physiological situation, where thrombo-inflammation is a prominent feature (e.g. monocyte migration to ischemic tissue).

Besides the regulation of monocyte function, platelets have been shown to regulate endothelial activation and migration at the site of vascular lesions. Platelets induce both endothelial activation and favour healing of vascular lesions via CXCL12-dependent endothelial migration and neo-endothelialization [46]. In the present study we found that in contrast to CXCL12, platelet-derived CXCL14 prevents endothelial migration as shown in scratch assays with endothelial monolayers in vitro. Given that platelet-derived CXCL14 functions as an angiostatic factor, this adds a new dimension to the potential of platelets and platelet derived mediators in regulating tumor progression and metastasis. However, to what extent platelet-derived CXCL14 might exert an impact on tumor suppression or invasiveness as compared to other platelet-derived anti-angiogenic factors like CXCL4 and endotstatin [10], remains to be elucidated. Presumably the relative abundance of these factors in platelets or in the immediate tumor microenvironment where platelet accumulate, their differential release kinetics and extent of release would govern their relative contribution in platelet regulated angiogenic processes.

To conclude it might be said that CXCL12 and CXCL14 are both prominent chemokines in platelets, and are both chemotactic for monocytes, but have different function at site of endothelial denudation (Fig. 5). We found that CXCL14 acts as an angiostatic chemokine in counteracting the angiogenic response of VEGF as has been shown before [20]. Therefore, platelet-dependent migration of monocytes and endothelial cells is a complex regulated system that involves at least 3 prominent chemokines (CXCL12, CXCL14) or chemokine-like

\section{KARGER}




\section{Cellular Physiology Cell Physiol Biochem 2017;41:1684-1696

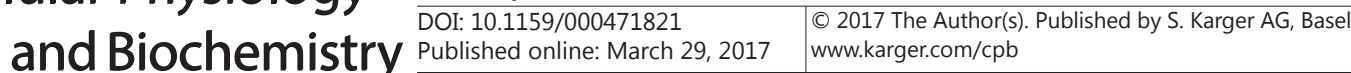

Witte et al.: Platelets as Source of CXCL14

compounds (MIF). Although their (patho)physiological role is increasingly recognized in a variety of diseases such as myocardial infarction or atherosclerosis their exact differential role remains to be defined.

\section{Acknowledgement}

The study was supported by the Deutsche Forschungsgemeinschaft "Klinische Forschergruppe KFO274 "Platelets - Basic mechanisms and translational implications" and Open Access Publishing Fund of Tuebingen University.

\section{Disclosure Statement}

The authors declare no conflict of interest.

\section{References}

1 Gawaz M, Langer H, May AE: Platelets in inflammation and atherogenesis. J Clin Invest 2005;115:33783384.

2 May AE, Seizer P, Gawaz M: Platelets: inflammatory firebugs of vascular walls. Arterioscler Thromb Vasc Biol 2008;28:s5-10.

3 Daub K, Langer H, Seizer P, Stellos K, May AE, Goyal P, Bigalke B, Schonberger T, Geisler T, Siegel-Axel D, Oostendorp RA, Lindemann S, Gawaz M: Platelets induce differentiation of human CD34+ progenitor cells into foam cells and endothelial cells. FASEB J 2006;20:2559-2561.

-4 Chatterjee M, von Ungern-Sternberg SN, Seizer P, Schlegel F, Buttcher M, Sindhu NA, Muller S, Mack A, Gawaz M: Platelet-derived CXCL12 regulates monocyte function, survival, differentiation into macrophages and foam cells through differential involvement of CXCR4-CXCR7. Cell Death Dis 2015;6:e1989.

-5 Massberg S, Konrad I, Schurzinger K, Lorenz M, Schneider S, Zohlnhoefer D, Hoppe K, Schiemann M, Kennerknecht E, Sauer S, Schulz C, Kerstan S, Rudelius M, Seidl S, Sorge F, Langer H, Peluso M, Goyal P, Vestweber D, Emambokus NR, Busch DH, Frampton J, Gawaz M: Platelets secrete stromal cell-derived factor 1alpha and recruit bone marrow-derived progenitor cells to arterial thrombi in vivo. J Exp Med 2006;203:1221-1233.

-6 Langer H, May AE, Daub K, Heinzmann U, Lang P, Schumm M, Vestweber D, Massberg S, Schonberger T, Pfisterer I, Hatzopoulos AK, Gawaz M: Adherent platelets recruit and induce differentiation of murine embryonic endothelial progenitor cells to mature endothelial cells in vitro. Circ Res 2006;98:e2-10. Stellos K, Bigalke B, Borst O, Pfaff F, Elskamp A, Sachsenmaier S, Zachmann R, Stamatelopoulos K, Schonberger T, Geisler T, Langer H, Gawaz M: Circulating platelet-progenitor cell coaggregate formation is increased in patients with acute coronary syndromes and augments recruitment of CD34+ cells in the ischaemic microcirculation. Eur Heart J 2013;34:2548-2556.

8 Stellos K, Gawaz M: Platelets and stromal cell-derived factor-1 in progenitor cell recruitment. Semin Thromb Hemost 2007;33:159-164.

-9 Chatterjee M, Gawaz M: Platelet-derived CXCL12 (SDF-1alpha): basic mechanisms and clinical implications. J Thromb Haemost 2013;11:1954-1967.

10 Chatterjee M, Huang Z, Zhang W, Jiang L, Hultenby K, Zhu L, Hu H, Nilsson GP, Li N: Distinct platelet packaging, release, and surface expression of proangiogenic and antiangiogenic factors on different platelet stimuli. Blood 2011;117:3907-3911.

11 Gawaz M, Vogel S: Platelets in tissue repair: control of apoptosis and interactions with regenerative cells. Blood 2013;122:2550-2554.

12 Kurth I, Willimann K, Schaerli P, Hunziker T, Clark-Lewis I, Moser B: Monocyte selectivity and tissue localization suggests a role for breast and kidney-expressed chemokine (BRAK) in macrophage development. J Exp Med 2001;194:855-861.

13 Schaerli P, Willimann K, Ebert LM, Walz A, Moser B: Cutaneous CXCL14 targets blood precursors to epidermal niches for Langerhans cell differentiation. Immunity 2005;23:331-342. 


\section{Cellular Physiology Cell Physiol Biochem 2017;41:1684-1696 \begin{tabular}{ll|l} 
and Biochemistry Published onlIne: IVIarch 29, 2017 & $\begin{array}{l}\text { (C) } 2017 \text { The Author(s). Published by S. Karger AG, Basel } \\
\text { www.karger.com/cpb }\end{array}$
\end{tabular}}

Witte et al.: Platelets as Source of CXCL14

-14 Frederick MJ, Henderson Y, Xu X, Deavers MT, Sahin AA, Wu H, Lewis DE, El-Naggar AK, Clayman GL: In vivo expression of the novel CXC chemokine BRAK in normal and cancerous human tissue. Am J Pathol 2000;156:1937-1950.

15 Salogni L, Musso T, Bosisio D, Mirolo M, Jala VR, Haribabu B, Locati M, Sozzani S: Activin A induces dendritic cell migration through the polarized release of CXC chemokine ligands 12 and 14. Blood 2009;113:5848-5856.

16 16 Cao X, Zhang W, Wan T, He L, Chen T, Yuan Z, Ma S, Yu Y, Chen G: Molecular cloning and characterization of a novel CXC chemokine macrophage inflammatory protein-2 gamma chemoattractant for human neutrophils and dendritic cells. J Immunol 2000;165:2588-2595.

17 Starnes T, Rasila KK, Robertson MJ, Brahmi Z, Dahl R, Christopherson K, Hromas R: The chemokine CXCL14 (BRAK) stimulates activated NK cell migration: implications for the downregulation of CXCL14 in malignancy. Exp Hematol 2006;34:1101-1105.

-18 Sleeman MA, Fraser JK, Murison JG, Kelly SL, Prestidge RL, Palmer DJ, Watson JD, Kumble KD: B cell- and monocyte-activating chemokine (BMAC), a novel non-ELR alpha-chemokine. Int Immunol 2000;12:677689.

19 Shurin GV, Ferris RL, Tourkova IL, Perez L, Lokshin A, Balkir L, Collins B, Chatta GS, Shurin MR: Loss of new chemokine CXCL14 in tumor tissue is associated with low infiltration by dendritic cells (DC), while restoration of human CXCL14 expression in tumor cells causes attraction of DC both in vitro and in vivo. J Immunol 2005;174:5490-5498.

20 Shellenberger TD, Wang M, Gujrati M, Jayakumar A, Strieter RM, Burdick MD, Ioannides CG, Efferson CL, ElNaggar AK, Roberts D, Clayman GL, Frederick MJ: BRAK/CXCL14 is a potent inhibitor of angiogenesis and a chemotactic factor for immature dendritic cells. Cancer Res 2004;64:8262-8270.

21 Padilla J, Jenkins NT, Lee S, Zhang H, Cui J, Zuidema MY, Zhang C, Hill MA, Perfield JW, 2nd, Ibdah JA, Booth FW, Davis JW, Laughlin MH, Rector RS: Vascular transcriptional alterations produced by juvenile obesity in Ossabaw swine. Physiol Genomics 2013;45:434-446.

22 Strussmann T, Tillmann S, Wirtz T, Bucala R, von Hundelshausen P, Bernhagen J: Platelets are a previously unrecognised source of MIF. Thromb Haemost 2013;110:1004-1013.

23 Chatterjee M, Geisler T: Inflammatory Contribution of Platelets Revisited: New Players in the Arena of Inflammation. Semin Thromb Hemost 2016;42:205-214.

24 Huising MO, Stet RJ, Kruiswijk CP, Savelkoul HF, Lidy Verburg-van Kemenade BM: Molecular evolution of CXC chemokines: extant CXC chemokines originate from the CNS. Trends Immunol 2003;24:307-313.

25 Lu J, Chatterjee M, Schmid H, Beck S, Gawaz M: CXCL14 as an emerging immune and inflammatory modulator. J Inflamm (Lond) 2016;13:1.

26 Seizer P, Ungern-Sternberg SN, Schonberger T, Borst O, Munzer P, Schmidt EM, Mack AF, Heinzmann D, Chatterjee M, Langer H, Malesevic M, Lang F, Gawaz M, Fischer G, May AE: Extracellular cyclophilin A activates platelets via EMMPRIN (CD147) and PI3K/Akt signaling, which promotes platelet adhesion and thrombus formation in vitro and in vivo. Arterioscler Thromb Vasc Biol 2015;35:655-663.

27 Vogel S, Bodenstein R, Chen Q, Feil S, Feil R, Rheinlaender J, Schaffer TE, Bohn E, Frick JS, Borst O, Munzer P, Walker B, Markel J, Csanyi G, Pagano PJ, Loughran P, Jessup ME, Watkins SC, Bullock GC, Sperry JL, Zuckerbraun BS, Billiar TR, Lotze MT, Gawaz M, Neal MD: Platelet-derived HMGB1 is a critical mediator of thrombosis. J Clin Invest 2015;125:4638-4654.

-28 Elvers M, Pozgaj R, Pleines I, May F, Kuijpers MJ, Heemskerk JM, Yu P, Nieswandt B: Platelet hyperreactivity and a prothrombotic phenotype in mice with a gain-of-function mutation in phospholipase Cgamma2. J Thromb Haemost 2010;8:1353-1363.

29 Muller I, Schonberger T, Schneider M, Borst O, Ziegler M, Seizer P, Leder C, Muller K, Lang M, Appenzeller F, Lunov O, Buchele B, Fahrleitner M, Olbrich M, Langer H, Geisler T, Lang F, Chatterjee M, de Boer JF, Tietge UJ, Bernhagen J, Simmet T, Gawaz M: Gremlin-1 is an inhibitor of macrophage migration inhibitory factor and attenuates atherosclerotic plaque growth in ApoE-/- Mice. J Biol Chem 2013;288:31635-31645.

- 30 Heinzmann D, Bangert A, Muller AM, von Ungern-Sternberg SN, Emschermann F, Schonberger T, Chatterjee M, Mack AF, Klingel K, Kandolf R, Malesevic M, Borst O, Gawaz M, Langer HF, Katus H, Fischer G, May AE, Kaya Z, Seizer P: The Novel Extracellular Cyclophilin A (CyPA) - Inhibitor MM284 Reduces Myocardial Inflammation and Remodeling in a Mouse Model of Troponin I -Induced Myocarditis. PLoS One 2015;10:e0124606. 


\section{Cellular Physiology Cell Physiol Biochem 2017;41:1684-1696 \begin{tabular}{l|l} 
DOI: 10.1159/000471821 & and Biochemistry 2017 The Author(s). Published by S. Karger AG, Basel \\
wublished
\end{tabular}}

Witte et al.: Platelets as Source of CXCL14

-31 Chatterjee M, Behrendt A, Schmid M, Beck S, Schneider M, Mack A, Muller I, Geisler T, Gawaz M: Platelets as a novel source of Gremlin-1: Implications for thromboinflammation. Thromb Haemost 2017;117:311-324.

32 Gawaz M, Neumann FJ, Schomig A: Evaluation of platelet membrane glycoproteins in coronary artery disease : consequences for diagnosis and therapy. Circulation 1999;99:E1-E11.

- 33 Borst O, Munzer P, Gatidis S, Schmidt EM, Schonberger T, Schmid E, Towhid ST, Stellos K, Seizer P, May AE, Lang F, Gawaz M: The inflammatory chemokine CXC motif ligand 16 triggers platelet activation and adhesion via CXC motif receptor 6-dependent phosphatidylinositide 3-kinase/Akt signaling. Circ Res 2012;111:1297-1307.

-34 Shao H, Lee S, Gae-Scott S, Nakata C, Chen S, Hamad AR, Chakravarti S: Extracellular matrix lumican promotes bacterial phagocytosis, and Lum-/- mice show increased Pseudomonas aeruginosa lung infection severity. J Biol Chem 2012;287:35860-35872.

-35 Langer HF, Gawaz M: Platelets in regenerative medicine. Basic Res Cardiol 2008;103:299-307.

-36 Muller KA, Chatterjee M, Rath D, Geisler T: Platelets, inflammation and anti-inflammatory effects of antiplatelet drugs in ACS and CAD. Thromb Haemost 2015;114:498-518.

37 Gleissner CA, von Hundelshausen P, Ley K: Platelet chemokines in vascular disease. Arterioscler Thromb Vasc Biol 2008;28:1920-1927.

- 38 Lindemann S, Tolley ND, Dixon DA, McIntyre TM, Prescott SM, Zimmerman GA, Weyrich AS: Activated platelets mediate inflammatory signaling by regulated interleukin 1beta synthesis. J Cell Biol 2001;154:485-490.

39 Gawaz M, Brand K, Dickfeld T, Pogatsa-Murray G, Page S, Bogner C, Koch W, Schomig A, Neumann F: Platelets induce alterations of chemotactic and adhesive properties of endothelial cells mediated through an interleukin-1-dependent mechanism. Implications for atherogenesis. Atherosclerosis 2000;148:75-85.

40 Murthy P, Durco F, Miller-Ocuin JL, Takedai T, Shankar S, Liang X, Liu X, Cui X, Sachdev U, Rath D, Lotze MT, Zeh HJ, 3rd, Gawaz M, Weber AN, Vogel S: The NLRP3 inflammasome and bruton's tyrosine kinase in platelets co-regulate platelet activation, aggregation, and in vitro thrombus formation. Biochem Biophys Res Commun 2017;483:230-236.

41 Wirtz TH, Tillmann S, Strussmann T, Kraemer S, Heemskerk JW, Grottke O, Gawaz M, von Hundelshausen P, Bernhagen J: Platelet-derived MIF: a novel platelet chemokine with distinct recruitment properties. Atherosclerosis 2015;239:1-10.

42 Salcedo R, Wasserman K, Young HA, Grimm MC, Howard OM, Anver MR, Kleinman HK, Murphy WJ, Oppenheim JJ: Vascular endothelial growth factor and basic fibroblast growth factor induce expression of CXCR4 on human endothelial cells: In vivo neovascularization induced by stromal-derived factor-1alpha. Am J Pathol 1999;154:1125-1135.

43 Tang YQ Yeaman MR, Selsted ME: Antimicrobial peptides from human platelets. Infect Immun 2002;70:6524-6533.

44 Coppinger JA, Cagney G, Toomey S, Kislinger T, Belton O, McRedmond JP, Cahill DJ, Emili A, Fitzgerald DJ, Maguire PB: Characterization of the proteins released from activated platelets leads to localization of novel platelet proteins in human atherosclerotic lesions. Blood 2004;103:2096-2104.

45 Otte M, Kliewer A, Schutz D, Reimann C, Schulz S, Stumm R: CXCL14 is no direct modulator of CXCR4. FEBS Lett 2014;588:4769-4775.

46 Gawaz M: Role of platelets in coronary thrombosis and reperfusion of ischemic myocardium. Cardiovasc Res 2004;61:498-511. 